\title{
SIRT1 overexpression is an independent prognosticator for patients with esophageal squamous cell carcinoma
}

\author{
Ming-Chun Ma', Tai-Jan Chiu', Hung-I Lu², Wan-Ting Huang ${ }^{3}$, Chien-Ming Lo², Wan-Yu Tien', Ya-Chun Lan', \\ Yen-Yang Chen ${ }^{1}$, Chang-Han Chen ${ }^{4,5,6}$ and Shau-Hsuan Li ${ }^{i^{*}}$
}

\begin{abstract}
Background: Sirtuin 1 (SIRT1) regulates DNA repair and metabolism by deacetylating target proteins. SIRT1 may be oncogenic because its overexpression has been detected in many cancers. The aim of the present study was to clarify the prognostic role of SIRT1 in patients with esophageal squamous cell carcinoma (ESCC) and evaluate the effect of SIRT1 inhibitor in vitro.

Methods: The expression of SIRT1 was evaluated immunohistochemically in 155 surgically resected ESCC and the staining results were evaluated semiquantitatively by the Immunoreactive Scoring System. The clinical features and treatment outcome were analyzed. The effect of SIRT1 inhibitor, SIRT 1 inhibitor IV, (S)-35, was investigated in vitro on ESCC cell lines.

Results: The expression of SIRT1 on ESCC did not correlate with age, gender, tumor location, stage, T classification, $\mathrm{N}$ classification, surgical margin or histology. Univariate analysis showed that SIRT1 overexpression was associated with inferior overall survival $(P=0.004)$ and disease-free survival $(P=0.004)$. In multivariate comparison, SIRT1 overexpression remained independently associated with worse overall survival $(P=0.009$, hazard ratio $=1.776)$ and disease-free survival $(P=0.017$, hazard ratio $=1.642)$. In cell lines, SIRT1 inhibitor inhibited ESCC growth.

Conclusions: Our study suggests that SIRT1 overexpression is an independent prognosticator for patients with ESCC and the SIRT1 inhibitor suppressed cell proliferation of ESCC cell lines. Our findings suggest that inhibition of SIRT1 signaling may be a promising novel target for ESCC.
\end{abstract}

Keywords: Esophageal squamous cell carcinoma, SIRT1, Overexpression

\section{Background}

The standard therapy for patients with esophageal squamous cell carcinoma (ESCC) is surgery and concurrent chemoradiothrapy [1-3]. Much improvement was achieved during the past decades. However, the tumor recurs despite of extensive surgery, and the prognosis was still unsatisfactory $[1,4,5]$. Identification of prognostic biomarkers for ESCC is crucial for clinicians to make risk-adapted treatment plans and the potential for novel target therapy.

\footnotetext{
* Correspondence: lee.a0928@msa.hinet.net

${ }^{1}$ Department of Hematology-Oncology, Kaohsiung Chang Gung Memorial Hospital and Chang Gung University College of Medicine, 123 Ta-Pei Road, Niaosong Dist, Kaohsiung, Taiwan, Republic of China

Full list of author information is available at the end of the article
}

Mammalian sirtuins deacetylases consist of seven family members (SIRT1-7) that have been shown to be critical regulators of cell signaling pathways [6, 7]. SIRT1 is a NAD +-dependent deacetylase that plays important roles in many biological processes, including stress response, apoptosis, cellular metabolism, adaptation to calorie restriction, aging, and tumorigenesis.

Because some members of the various classes of histone deacetylases (HDACs) have been shown to be overexpressed in diverse cancers, current views suggest that perturbed acetylation patterns on proteins may contribute to cellular transformation and tumor progression $[6,8,9]$. SIRT1 can activate stress defense and DNA repair mechanisms, and therefore aids in the preservation of genomic integrity $[10,11]$. SIRT1 also functions in the regulation of

(C) The Author(s). 2018 Open Access This article is distributed under the terms of the Creative Commons Attribution 4.0 International License (http://creativecommons.org/licenses/by/4.0/), which permits unrestricted use, distribution, and 
metabolism and maintaining the integrity of the genome, and thus has been described as a potential tumor suppressor [11]. For example, both breast cancer and hepatocellular carcinoma exhibit reduced SIRT1 levels compared with normal tissues [12]. Wang et al. [12] demonstrated that Sirt1(+/-); p53(+/-) mice develop tumors in multiple tissues, whereas activation of SIRT1 by resveratrol treatment reduces tumorigenesis, and thus suggested that SIRT1 may act as a tumor suppressor through its role in DNA damage response and genome integrity. Previous study [11] also showed that SIRT1 activity is required for suppressing survivin transcription, and reduction of survivin via SIRT1 activity may play an important role in breast cancer susceptibility gene 1 (BRCA1)-associated mammary tumor formation. Conversely, other studies showed that overexpression of SIRT1 caused the suppression of DNA damage repair proteins and factors involved in tumor suppression, and thus led to increased tumor growth and cell survival $[11,13]$. Previous studies [11] revealed that SIRT1mediated deacetylation suppresses the functions of several tumor suppressors, including p53, p73, and hypermethylated in cancer 1 (HIC1). Upregulation of SIRT1 has been reported in various human malignancies including prostate cancer, breast cancer, lung cancer, lymphoma, leukemia, soft tissue sarcomas, colon cancer, and gastric cancer [11, 14-19]. In recent years, a number of inhibitors have been discovered and characterized. This raises the possibility that SIRT1 inhibition might suppress cancer cell proliferation [11]. However, the role of SIRT1 in ESCC remains largely undefined. Therefore, we conducted the present study to evaluate the prognostic significance of SIRT1 in patients with ESCC by immunohistochemistry and investigate the effect of SIRT1 inhibitor in vitro.

\section{Methods}

\section{Patient population}

Patients with ESCC who received surgical resection at Kaohsiung Chang Gung Memorial Hospital were reviewed retrospectively. This study was approved by the Institutional Review Board of Chang Gung Memorial Hospital. The approval number of this project was 201800339B0. Patients with second malignancy and who receiving chemotherapy and/or radiotherapy before surgery were excluded. We identified 155 patients with available paraffin blocks and follow-up. Patients underwent a radical esophagectomy with cervical esophagogastric anastomosis (McKeown procedure) or an Ivor Lewis esophagectomy with intrathoracic anastomosis, reconstruction of the digestive tract with gastric tube, and pylorus drainage procedures. Two-field lymph node dissection was performed in all patients. The pathologic TNM stage was determined according to the 7th American Joint Committee on Cancer (AJCC) staging system. After surgery, patients were followed at 3-month intervals for 2 years, 6-month intervals up to year 5, and annually thereafter. Diseasefree survival (DFS) was calculated from the time of operation to the recurrence or death from any cause without evidence of recurrence. Overall survival (OS) was calculated from the time of operation to death as a result of all causes.

\section{Immunohistochemistry}

Immunohistochemistry was used to evaluate the expression of SIRT1. Formalin-fixed and paraffin-embedded 4$\mu \mathrm{m}$ thick tumor tissue slices were dewaxed and rehydrated before antigen retrieval. The microwave antigen retrieval method was then utilized, and the slides were immersed in EDTA antigen retrieval solution ( $\mathrm{pH} 9.0)$ for $15 \mathrm{~min}$. Subsequently, we added 3\% hydrogen peroxide to the slides to inhibit endogenous peroxidase activity. Subsequently, SIRT1 (1:150; Abcam, Cambridge, UK) was applied to the sections that were later incubated at $4{ }^{\circ} \mathrm{C}$ overnight. On the second day, biotinylated antibody and streptavidinperoxidase reagent were successively applied for $15 \mathrm{~min}$ each at $37^{\circ} \mathrm{C}$. Finally, 3,3'-diaminobenzidine tetrahydrochloride (DAB) was used for visualization, and hematoxylin was added as a counterstain. The positive controls were human non-small cell lung cancer tissues expressing SIRT1. Sections that were incubated with PBS instead of primary antibodies were used as negative controls. Both the positive and negative controls were used to evaluate the reliability of staining and exclude nonspecific reactions. The expression level of SIRT1 protein was calculated utilizing a semiquantitative scoring system. The staining score was classified as 0 (negative staining), 1 (weak staining), 2 (moderate staining) and 3 (strong staining). The quantity score, which represented the percentage of cancer cells that were positively stained, was calculated as follows: 0 (0-5\%), 1 (6-25\%), 2 (26-50\%), 3 (51-75\%), and $4(\geq 76 \%)$. By multiplying the staining score by the quantity score of each slide, the final semiquantitative score was obtained (ranging from 0 to 12). Scores that ranged from 4 to 12 were considered to represent overexpression.

\section{Cell culture and 3-(4.5-dimethylthiazol-2-yl)-2,5- diphenyltetrazolium bromide assay}

Human esophageal squamous cell carcinoma cell line KYSE 270 and KYSE 70 were obtained from the European Collection of Authenticated Cell Cultures (ECACC). The KYSE 270 cell line was maintained in RPMI 1640 (Invitrogen, Carlsbad, CA) and Ham's F12 (Nissui Pharmaceutical, Tokyo, Japan) mixed (1:1) medium containing $2 \%$ fetal bovine serum. The KYSE 70 cell line was maintained in RPMI 1640 medium (Invitrogen, Carlsbad, CA) medium containing $10 \%$ fetal bovine serum. To test the effects of cell proliferation of SIRT1 inhibitor, SIRT 1 inhibitor IV, (S)-35 (Calbiochem, Merck Millipore, Darmstadt, Germany), cells 
were plated into 96-well, flat bottomed plates at $3 \times$ $10^{3}$ cells per $100 \mathrm{~mL}$ per well in the recommended medium containing $10 \%$ fetal bovine serum. After overnight incubation, triplicate wells were treated with different concentrations of SIRT1 inhibitor $(0,5$, 10 and $20 \mu \mathrm{M}$ ) for $24 \mathrm{~h}$. The relative percentages of metabolically active cells compared with untreated controls were then determined on the basis of mitochondrial conversion of 3- (4.5-dimethylthiazol-2-yl)2,5-diphenyltetrazolium bromide (MTT) to formazine. In brief, after incubation, $10 \mathrm{~mL}$ of MTT (Sigma, St Louis, MO) solution ( $5 \mathrm{mg} / \mathrm{mL}$ ) was added to each well for $3 \mathrm{~h}$, and the medium was then replaced with $150 \mathrm{~mL}$ of dimethylsulfoxide per well. Results were assessed in a 96well format plate reader by measuring the absorbance at a wavelength of $540 \mathrm{~nm}$ using a Titertek Multiscan (Thermo, Vantaa, Finland).

\section{Statistical analysis}

The SPSS software package (18.0; SPSS, Chicago, IL, USA) was used for statistical analysis. Correlations among SIRT1 and various clinicopathologic characteristics were compared using the chi-square test. Survival curves were constructed using the Kaplan-Meier method, and the significance of differences in the survival of subgroups was examined with the log rank test. Independent prognostic factors were determined by multivariate Cox regression analysis. $P$ values less than 0.05 were considered significant.

\section{Results}

\section{Patient characteristics}

The median age for the 155 patients (150 men and 5 women) was 55 years (range, 29-77). The 7th AJCC stages of 155 patients with ESCC were stage I in 44 patients, stage II in 68, stage III in 39, and stage IV in 4 (Table 1). The histologic grading was grade 1 in 16 patients, grade 2 in 108, and grade 3 in 31. The tumor locations were upper esophagus in 22 patients, middle in 60 , and lower in 73 . At the time of analysis, the median periods of follow-up were 65.8 months (range, 50.4 238 months) for the 50 survivors and 37.6 months (range, 0.9 238 months) for all 155 patients. The 3-year OS and DFS rates for these 155 patients were $52 \%$ and $43 \%$, respectively. The 5 -year OS and DFS rates for these 155 patients were $44 \%$ and $37 \%$, respectively.

\section{Correlation between clinicopathologic parameters and SIRT1 expression}

Among the 155 patients, SIRT1 overexpression was identified in 77 (55\%) patients (Fig. 1). There was no correlation between the clinicopathological factors and the IHC expression of SIRT1 (Table 2).
Table 1 Characteristics of 155 patients with esophageal squamous cell carcinoma receiving esophagectomy

\begin{tabular}{|c|c|c|}
\hline \multirow[t]{3}{*}{ Age } & median & 55 \\
\hline & mean & 56.2 \\
\hline & range & $29 \sim 77$ \\
\hline \multirow[t]{2}{*}{ Sex } & male & $150(97 \%)$ \\
\hline & female & $5(3 \%)$ \\
\hline \multirow[t]{3}{*}{ Primary tumor location } & Upper & $22(14 \%)$ \\
\hline & Middle & 60 (39\%) \\
\hline & Lower & $73(47 \%)$ \\
\hline \multirow[t]{4}{*}{ T classification } & $\mathrm{T} 1$ & 48 (31\%) \\
\hline & $\mathrm{T} 2$ & $31(20 \%)$ \\
\hline & T3 & $61(39 \%)$ \\
\hline & $\mathrm{T} 4$ & $15(10 \%)$ \\
\hline \multirow[t]{4}{*}{ N classification } & NO & $106(68 \%)$ \\
\hline & N1 & 30 (19\%) \\
\hline & N2 & $13(9 \%)$ \\
\hline & N3 & $6(4 \%)$ \\
\hline \multirow[t]{8}{*}{$7^{\text {th }}$ AJCC Stage } & IA & $7(5 \%)$ \\
\hline & IB & $37(24 \%)$ \\
\hline & $\| \mathrm{A}$ & $25(16 \%)$ \\
\hline & $\| B$ & $43(28 \%)$ \\
\hline & $\| I I A$ & $15(9 \%)$ \\
\hline & $\| I \mid B$ & $6(4 \%)$ \\
\hline & IIIC & $18(12 \%)$ \\
\hline & IV & $4(2 \%)$ \\
\hline \multirow[t]{3}{*}{ Histological grading } & Grade 1 & $16(10 \%)$ \\
\hline & Grade 2 & $108(70 \%)$ \\
\hline & Grade 3 & $31(20 \%)$ \\
\hline \multirow[t]{2}{*}{ Surgical margin } & Negative & $135(87 \%)$ \\
\hline & Positive & $20(13 \%)$ \\
\hline \multirow[t]{2}{*}{ SIRT1 expression } & Low expression & $78(50 \%)$ \\
\hline & Overexpression & 77 (50\%) \\
\hline
\end{tabular}

AJCC American Joint Committee on Cancer, SIRT1 Sirtuin1

\section{Survival analyses}

Correlations of clinicopathologic parameters and SIRT1 with OS and DFS are shown in Table 3. Univariate analyses demonstrated that 7 th AJCC stage III + IV $(P<0.001)$, T3 +4 disease $(P<0.001)$, positive regional lymph node $(P<0.001)$, histological grading $3(P=$ $0.001)$, positive surgical margin $(P=0.023)$, SIRT1 overexpression $(P=0.004$, Fig. 2a) were associated with inferior OS. Additionally, 7th AJCC stage III + IV, T3 + 4 disease $(P<0.001)$, histological grading $3(P=0.002)$, positive regional lymph node $(P<0.001)$, positive surgical margin $(P=0.046)$ and SIRT1 overexpression $(P=0.004$, Fig. $2 \mathrm{~b})$ were associated with inferior DFS. The 3-year OS and DFS rates were $63 \%$ and $54 \%$ in patients with 


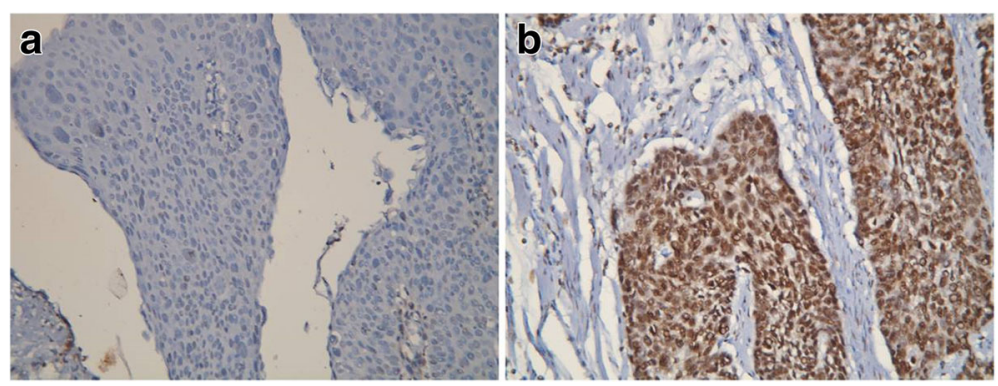

Fig. $1 \mathrm{Imm}$ unohistochemical staining of SIRT1. a Low expression of SIRT1. b Overexpression of SIRT1. Original magnification $\times 200$

low expression of SIRT1 and 39\% and 33\% in patients with overexpression of SIRT1, respectively. The 5-year OS and DFS rates were 55\% and $49 \%$ in patients with low expression of SIRT1 and 34\% and $26 \%$ in patients with overexpression of SIRT1, respectively.

In multivariate comparisons, SIRT1 overexpression $(P=0.009$, hazard ratio $[\mathrm{HR}], 1.776,95 \% \mathrm{CI}, 1.152-2.747)$ and $\mathrm{T} 3+4$ disease $(P=0.002$, hazard ratio $[\mathrm{HR}], 2.250$, 95\% CI, 1.339-3.782) remained independently associated with inferior OS (Table 4). For DFS, SIRT1 overexpression $(P=0.017$; HR, 1.642; 95\% CI, 1.093-2.463), T3 + 4 disease $(P=0.005$, hazard ratio $[\mathrm{HR}], 2.011,95 \% \mathrm{CI}, 1.240-$ $3.261)$, positive regional lymph node $(P=0.035$; HR, 1.967; 95\% CI, 1.048-3.691) represented an independent adverse prognostic factor.

Table 2 Associations between SIRT1 expressions and clinicopathological parameters in 155 patients with esophageal squamous cell carcinoma receiving esophagectomy

\begin{tabular}{|c|c|c|c|c|}
\hline \multirow[t]{2}{*}{ Parameters } & & \multicolumn{3}{|c|}{ SIRT1 expression } \\
\hline & & Low & Over & $P$ value \\
\hline \multirow[t]{2}{*}{ Age } & $<55 \mathrm{y} / 0$ & 32 & 37 & 0.38 \\
\hline & $\geqq 55 \mathrm{y} / 0$ & 46 & 40 & \\
\hline \multirow[t]{2}{*}{ Sex } & Male & 75 & 75 & 1.00 \\
\hline & Female & 3 & 2 & \\
\hline \multirow[t]{2}{*}{ Primary tumor location } & $U+M$ & 40 & 42 & 0.68 \\
\hline & L & 38 & 35 & \\
\hline \multirow[t]{2}{*}{ T classification } & $\mathrm{T} 1+\mathrm{T} 2$ & 45 & 34 & 0.092 \\
\hline & $\mathrm{T} 3+\mathrm{T} 4$ & 33 & 43 & \\
\hline \multirow[t]{2}{*}{ N classification } & NO & 55 & 51 & 0.57 \\
\hline & $\mathrm{N} 1+2+3$ & 23 & 26 & \\
\hline \multirow[t]{2}{*}{$7^{\text {th }}$ AJCC Stage } & $\mid+\|$ & 57 & 55 & 0.82 \\
\hline & $I I I+I V$ & 21 & 22 & \\
\hline \multirow[t]{2}{*}{ Histological grading } & Grade $1+2$ & 66 & 58 & 0.15 \\
\hline & Grade 3 & 12 & 19 & \\
\hline \multirow[t]{2}{*}{ Surgical margin } & Negative & 75 & 60 & 0.38 \\
\hline & Positive & 9 & 11 & \\
\hline
\end{tabular}

AJCC American Joint Committee on Cancer, SIRT1 Sirtuin1, p-p70S6K phosphorylated p70 ribosomal $\mathrm{S} 6$ protein kinase
The SIRT1 inhibitor suppressed cell proliferation of ESCC cell lines

Results on whether the SIRT1 inhibitor would suppress cell proliferation in ESCC cell line KYSE 270 and KYSE 70 show that the SIRT1 inhibitor, SIRT 1 inhibitor IV, (S)-35, displayed a dose-dependent, growth-inhibitory effect in both ESCC cell lines (Fig. 3a and b).

\section{Discussion}

It is well known that advanced stage, higher histologic grade and residual disease after surgery lead to poor prognosis [1, 4, 5], and our study also showed the same result. In our study, we demonstrated that SIRT1 overexpression was an independent poor prognosticator for clinical outcome, and SIRT1 inhibitor suppressed cell proliferation of ESCC cell lines. Previous studies in several types of cancers [20-38] also showed SIRT1 overexpression was correlated with advanced stages or poor prognosis and inhibition of SIRT1 may suppress tumor progression. There are several possible mechanisms involved in SIRT1 mediated tumor progression. First, Liu et al. $[18,20]$ reported that SIRT1 can maintain silent chromatin via the deacetylation of histone proteins, and thus protect cells from apoptosis. Second, SIRT1 can repress tumor suppressor genes, such as p53, p27 $7^{\text {kip1 }}$, and FOXO family members, either by directly binding and deacetylating these non-histone proteins or by inducing heritable $\mathrm{CpG}$ island methylation at the gene promoter [18, 20, 30]. For example, previous studies $[18,20]$ showed that SIRT1 binds $\mathrm{p} 53$ and deacetylates its C-terminal Lys382, resulting in inhibition of p53 induction of cell cycle arrest and apoptosis in response to DNA damage and oxidative stress. Zhu et al. [30] reported that SIRT1 is an important regulator of p27 $7^{\text {kip } 1}$ and SIRT inhibition induces senescence and antigrowth potential in lung cancer. Third, Byles et al. [27] also found that SIRT1 can enhance metastatic potential by inducing epithelialmesenchymal transition in prostate cancer. Fourth, previous studies [29, 31] showed that SIRT1 is involved in chemotherapy resistance. Liang et al. [29] suggest that reduced glucose use and altered mitochondrial metabolism 
Table 3 Results of univariate log-rank analysis of prognostic factors for overall survival and disease-free survival in 155 patients with esophageal squamous cell carcinoma receiving esophagectomy

\begin{tabular}{|c|c|c|c|c|c|}
\hline \multirow[t]{2}{*}{ Factors } & \multirow{2}{*}{$\begin{array}{l}\text { No. of } \\
\text { patients }\end{array}$} & \multicolumn{2}{|c|}{ Overall survival (OS) } & \multicolumn{2}{|c|}{ Disease-free survival (DFS) } \\
\hline & & 5 -yr OS rate (\%) & $P$ value & 5-yr DFS rate (\%) & $P$ value \\
\hline \multicolumn{6}{|l|}{ Age } \\
\hline$<55 \mathrm{y} / 0$ & 69 & $54 \%$ & 0.19 & $48 \%$ & 0.10 \\
\hline$\geqq 55 \mathrm{y} / 0$ & 86 & $37 \%$ & & $29 \%$ & \\
\hline \multicolumn{6}{|l|}{ Location } \\
\hline$U+M$ & 82 & $45 \%$ & 0.84 & $35 \%$ & 0.46 \\
\hline L & 73 & $44 \%$ & & $40 \%$ & \\
\hline \multicolumn{6}{|l|}{ T classification } \\
\hline $\mathrm{T} 1+2$ & 79 & $64 \%$ & $<0.001^{\mathrm{a}}$ & $52 \%$ & $<0.001^{\mathrm{a}}$ \\
\hline $\mathrm{T} 3+4$ & 76 & $24 \%$ & & $22 \%$ & \\
\hline \multicolumn{6}{|l|}{ N classification } \\
\hline NO & 106 & $56 \%$ & $<0.001^{\mathrm{a}}$ & $47 \%$ & $<0.001^{\mathrm{C}}$ \\
\hline $\mathrm{N} 1+2+3$ & 49 & $20 \%$ & & $16 \%$ & \\
\hline \multicolumn{6}{|l|}{$7^{\text {th }}$ AJCC stage } \\
\hline $1+\|$ & 112 & $55 \%$ & $<0.001^{\mathrm{a}}$ & $46 \%$ & $<0.001^{\mathrm{a}}$ \\
\hline$I I I+I V$ & 43 & $16 \%$ & & $16 \%$ & \\
\hline \multicolumn{6}{|l|}{ Histological grading } \\
\hline Grade $1+2$ & 124 & $51 \%$ & $0.001^{\mathrm{a}}$ & $43 \%$ & $0.002^{\circ}$ \\
\hline Grade 3 & 31 & $19 \%$ & & $16 \%$ & \\
\hline \multicolumn{6}{|l|}{ Surgical margin } \\
\hline Negative & 135 & $47 \%$ & $0.023^{\mathrm{a}}$ & $39 \%$ & $0.046^{2}$ \\
\hline Positive & 20 & $25 \%$ & & $25 \%$ & \\
\hline \multicolumn{6}{|l|}{ SIRT1 expression } \\
\hline Low expression & 78 & $55 \%$ & $0.004^{\mathrm{a}}$ & $49 \%$ & $0.004^{\circ}$ \\
\hline Overexpression & 77 & $34 \%$ & & $26 \%$ & \\
\hline
\end{tabular}

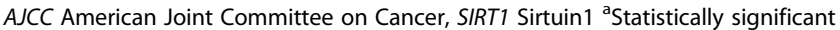
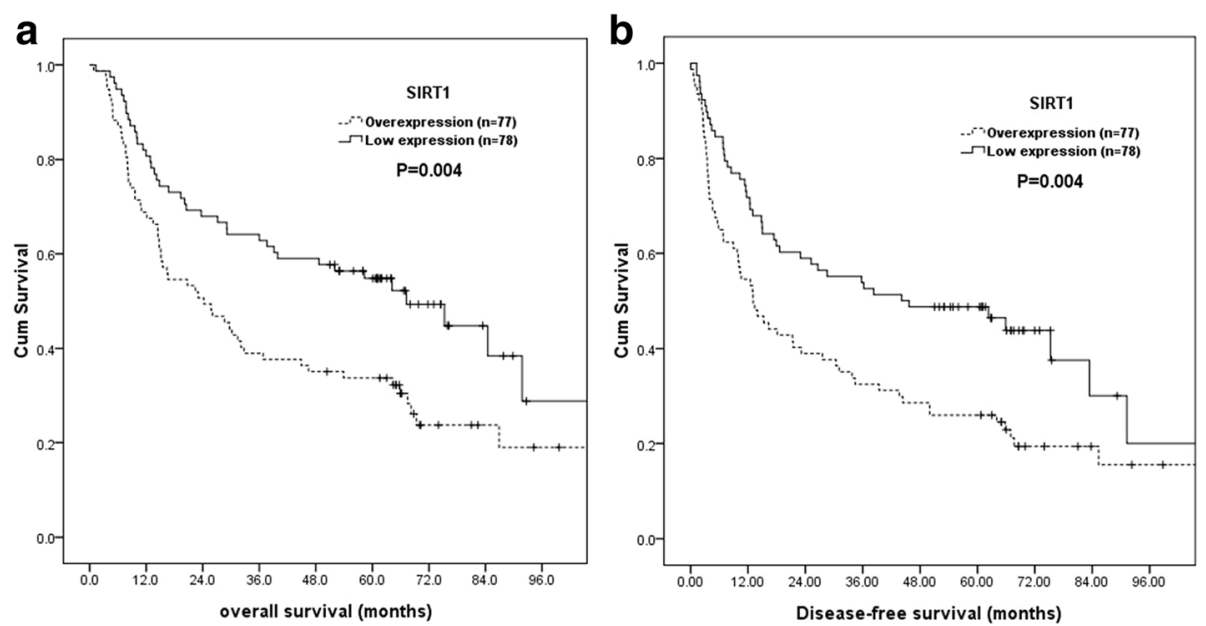

Fig. 2 Kaplan-Meier curves according to SIRT1 status. a Overall survival according to SIRT1 status. b Disease-free survival according to SIRT1 status 
Table 4 Results of multivariate Cox regression analysis for overall survival and disease-free survival in155 patients with esophageal squamous cell carcinoma

\begin{tabular}{|c|c|c|c|c|}
\hline \multirow[t]{2}{*}{ Factors } & \multicolumn{2}{|l|}{ Overall survival } & \multicolumn{2}{|l|}{ Disease-free survival } \\
\hline & $\mathrm{HR}(95 \% \mathrm{Cl})$ & $P$ value & $\mathrm{HR}(95 \% \mathrm{Cl})$ & $P$ value \\
\hline $\mathrm{T} 3+4$ & $2.250(1.339-3.782)$ & $0.002^{a}$ & $2.011(1.240-3.261)$ & $0.005^{a}$ \\
\hline SIRT1 expression & $1.776(1.152-2.747)$ & $0.009^{\mathrm{a}}$ & $1.642(1.093-2.463)$ & $0.017^{\mathrm{a}}$ \\
\hline $\mathrm{N} 1+2+3$ & - & - & $1.967(1.048-3.691)$ & $0.035^{\mathrm{a}}$ \\
\hline
\end{tabular}

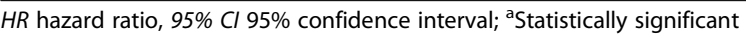

mediated by SIRT1 may contribute to cisplatin resistance. Taken together, the results from our study, together with previous findings, suggest that SIRT1 is not only an adverse prognosticator but also a potential novel therapeutic target.

Despite advance in perioperative management and surgical techniques, the prognosis of patients with ESCC remains poor [1, 2]. Even after radical surgery, patients still develop recurrences and metastases. Over the past decades, several post-operative adjuvant therapy clinical trials were performed to improve unsatisfactory cure rate achieved with surgery alone. Hence, identifying patients at high risk for recurrence who may benefit from post-operative adjuvant therapy is principal. In our study, overexpression of

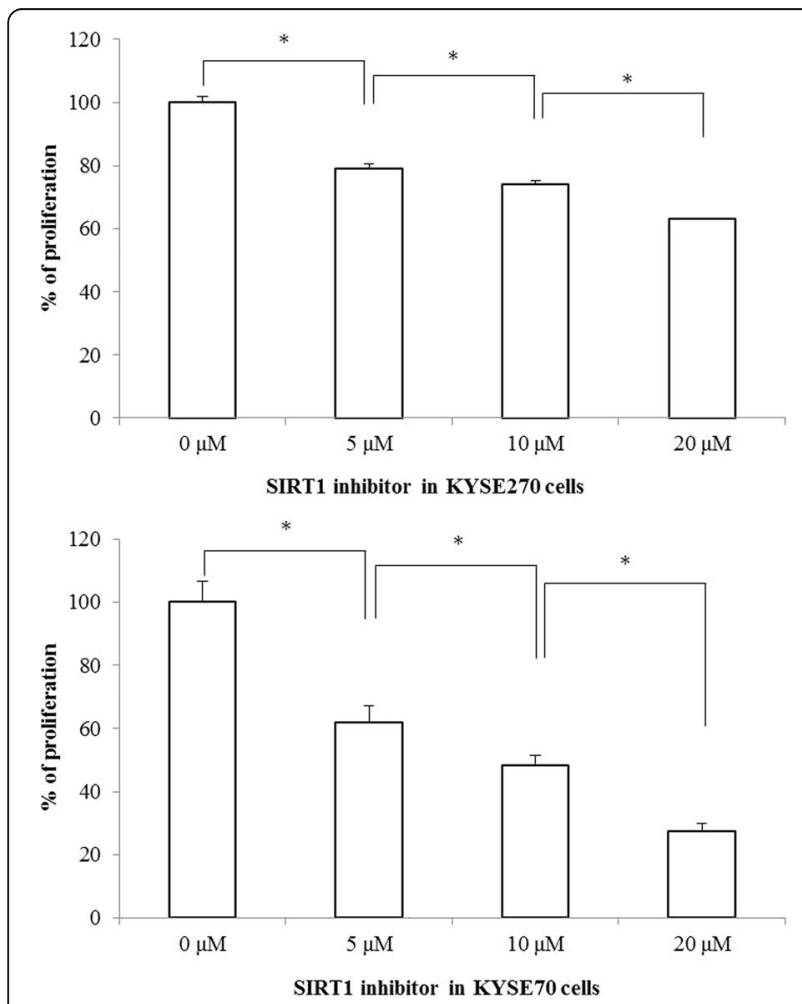

Fig. 3 SIRT1 inhibitor displayed a proliferation-inhibitory effect in a dose-dependent manner in KYSE270 and KYSE70 esophageal squamous cell carcinoma cell lines. *Statistically significant difference in growth inhibition. Any $p$ value $<0.05$ was considered statistically significant. Columns, mean; bars, SD
SIRT1 was highly representative of biological aggressiveness and independently associated with worse disease-free survival. The 5 -year disease-free survival rate was only $26 \%$ in patients with SIRT1 overexpression, indicating that SIRT1 status may be used to select some patients for adjuvant therapy after esophagectomy.

\section{Conclusions}

Higher expression of SIRT1 is an independent prognosticator for patients with ESCC. The SIRT1 inhibitor suppressed cell proliferation of ESCC in vitro. Our findings suggest that Sirtuin inhibitors may be a potential therapy in ESCC patients with SIRT1 overexpression. There were two limitations in our study. First, the patient number was small and was retrospectively analyzed. Second, the effect of SIRT1 inhibitor was analyzed in cell line. The results need further studies to confirm our findings.

\section{Abbreviations}

AJCC: American Joint Committee on Cancer; DAB: Diaminobenzidine tetrahydrochloride; DFS: Disease-free survival; DNA: Deoxyribonucleic acid; ECACC: European collection of authenticated cell cultures; EDTA: Ethylene diamine tetraacetie acid; ESCC: Esophageal squamous cell carcinoma; HDAC: Histone deacetylases; HR: Hazard ratio; MTT: diphenyltetrazolium bromide; NDA: Nicotinamide adenine dinucleotide; OS: Overall survival; PBS: Phosphate buffered saline; pH: potential of hydrogen; SIRT1: Sirtuin 1; TNM: Tumor, nodes and metastasis

\section{Acknowledgements}

This work was supported in part by grants from the National Science Council, Taiwan (MOST 106-2314-B-182A-159-MY3 and MOST 106-2320-B-182A-015) and Chang Gung Memorial Hospital (CMRPG8E1533 and CMRPG8G0891).

\section{Funding}

This work was supported in part by grants from the National Science Council, Taiwan (MOST 106-2314-B-182A-159-MY3 and MOST 106-2320-B-182A-015) and Chang Gung Memorial Hospital (CMRPG8E1533 and CMRPG8G0891).

\section{Availability of data and materials}

The datasets analyzed during the current study are not publicly available but are available from the corresponding author on reasonable request.

\section{Authors' contributions}

SHL conceptualized the study. CHC contributed to the study design. HIL, CML, WTH, YYC, TJC and SHL acquired the data. WYT and YCL analyzed and interpreted the data. SHL contributed to the statistical analysis. SHL and MCM prepared the manuscript. TJC and YYC edited the manuscript. WTH reviewed the manuscript. All authors read and approved the final manuscript. 


\section{Ethics approval and consent to participate}

The Institutional Review Board of Chang Gung Memorial Hospital approved the present study.

\section{Competing interests}

The authors declare that they have no competing interests.

\section{Publisher's Note}

Springer Nature remains neutral with regard to jurisdictional claims in published maps and institutional affiliations.

\section{Author details}

'Department of Hematology-Oncology, Kaohsiung Chang Gung Memorial Hospital and Chang Gung University College of Medicine, 123 Ta-Pei Road, Niaosong Dist, Kaohsiung, Taiwan, Republic of China. ${ }^{2}$ Department of Thoracic \& Cardiovascular Surgery, Kaohsiung Chang Gung Memorial Hospital and Chang Gung University College of Medicine, Kaohsiung, Taiwan, Republic of China. ${ }^{3}$ Department of Pathology, Kaohsiung Chang Gung Memorial Hospital and Chang Gung University College of Medicine, Kaohsiung, Taiwan, Republic of China. ${ }^{4}$ Institute for Translational Research in Biomedicine, Kaohsiung Chang Gung Memorial Hospital, Kaohsiung, Taiwan, Republic of China. ${ }^{5}$ Department of Applied Chemistry, and Graduate Institute of Biomedicine and Biomedical Technology, National Chi Nan University, Nantou, Taiwan, Republic of China. ${ }^{6}$ Center for Infectious Disease and Cancer Research, Kaohsiung Medical University, Kaohsiung, Taiwan, Republic of China.

\section{Received: 4 August 2017 Accepted: 5 April 2018}

\section{Published online: 10 April 2018}

\section{References}

1. Li SH, Chen CH, Lu HI, Huang WT, Tien WY, Lan YC, Lee CC, Chen YH, Huang HY, Chang AY, et al. Phosphorylated p70S6K expression is an independent prognosticator for patients with esophageal squamous cell carcinoma. Surgery. 2015;157(3):570-80.

2. Lu HI, Li SH, Huang WT, Rau KM, Fang FM, Wang YM, Lin WC, Tien WY. A comparative study of isolated and metachronous oesophageal squamous cell carcinoma with antecedent upper aerodigestive tract cancer. Eur J Cardiothorac Surg. 2013;44(5):860-5.

3. Li SH, Rau KM, Lu HI, Wang YM, Tien WY, Liang JL, Lin WC. Pre-treatment maximal oesophageal wall thickness is independently associated witeh response to chemoradiotherapy in patients with T3-4 oesophageal squamous cell carcinoma. Eur J Cardiothorac Surg. 2012;42(6):958-64.

4. Rutegard M, Charonis K, Lu Y, Lagergren P, Lagergren J, Rouvelas I. Population-based esophageal cancer survival after resection without neoadjuvant therapy: an update. Surgery. 2012;152(5):903-10.

5. Baba Y, Watanabe M, Shigaki H, Iwagami S, Ishimoto T, Iwatsuki M, Baba H. Negative lymph-node count is associated with survival in patients with resected esophageal squamous cell carcinoma. Surgery. 2013; 153(2):234-41.

6. Simmons GE Jr, Pruitt WM, Pruitt K. Diverse roles of SIRT1 in cancer biology and lipid metabolism. Int J Mol Sci. 2015;16(1):950-65.

7. Haberland M, Montgomery RL, Olson EN. The many roles of histone deacetylases in development and physiology: implications for disease and therapy. Nat Rev Genet. 2009:10(1):32-42.

8. Krusche CA, Wulfing P, Kersting C, Vloet A, Bocker W, Kiesel L, Beier HM, Alfer J. Histone deacetylase-1 and -3 protein expression in human breast cancer: a tissue microarray analysis. Breast Cancer Res Treat. 2005;90(1):15-23.

9. Weichert W, Roske A, Niesporek S, Noske A, Buckendahl AC, Dietel M, Gekeler V, Boehm M, Beckers T, Denkert C. Class I histone deacetylase expression has independent prognostic impact in human colorectal cancer: specific role of class I histone deacetylases in vitro and in vivo. Clin. Cancer Res. 2008;14(6):1669-77.

10. Bordone L, Guarente L. Calorie restriction, SIRT1 and metabolism: understanding longevity. Nat Rev Mol Cell Biol. 2005;6(4):298-305

11. Kozako T, Suzuki T, Yoshimitsu M, Arima N, Honda S, Soeda S. Anticancer agents targeted to sirtuins. Molecules (Basel, Switzerland). 2014;19(12): 20295-313.

12. Wang RH, Sengupta K, Li C, Kim HS, Cao L, Xiao C, Kim S, Xu X, Zheng Y, Chilton $\mathrm{B}$, et al. Impaired DNA damage response, genome instability, and tumorigenesis in SIRT1 mutant mice. Cancer Cell. 2008;14(4):312-23.
13. Chu F, Chou PM, Zheng X, Mirkin BL, Rebbaa A. Control of multidrug resistance gene $\mathrm{mdr} 1$ and cancer resistance to chemotherapy by the longevity gene sirt1. Cancer Res. 2005;65(22):10183-7.

14. Derr RS, van Hoesel AQ, Benard A, Goossens-Beumer IJ, Sajet A, DekkerEnsink NG, de Kruijf EM, Bastiaannet E, Smit VT, van de Velde CJ, et al. High nuclear expression levels of histone-modifying enzymes LSD1, HDAC2 and SIRT1 in tumor cells correlate with decreased survival and increased relapse in breast cancer patients. BMC Cancer. 2014;14:604.

15. Han L, Liang XH, Chen LX, Bao SM, Yan ZQ. SIRT1 is highly expressed in brain metastasis tissues of non-small cell lung cancer (NSCLC) and in positive regulation of NSCLC cell migration. Int J Clin Exp Pathol. 2013;6(11):2357-65.

16. Chen W, Bhatia R. Roles of SIRT1 in leukemogenesis. Curr Opin Hematol. 2013:20(4):308-13.

17. Huffman DM, Grizzle WE, Bamman MM, Kim JS, Eltoum IA, Elgavish A, Nagy TR. SIRT1 is significantly elevated in mouse and human prostate cancer. Cancer Res. 2007;67(14):6612-8.

18. Liu T, Liu PY, Marshall GM. The critical role of the class III histone deacetylase SIRT1 in cancer. Cancer Res. 2009;69(5):1702-5.

19. Kozako T, Aikawa A, Shoji T, Fujimoto T, Yoshimitsu M, Shirasawa S, Tanaka $\mathrm{H}$, Honda S, Shimeno $\mathrm{H}$, Arima $\mathrm{N}$, et al. High expression of the longevity gene product SIRT1 and apoptosis induction by sirtinol in adult T-cell leukemia cells. Int J Cancer. 2012;131(9):2044-55.

20. Li K, Luo J. The role of SIRT1 in tumorigenesis. N. Am. J. Med. Sci. 2011:4(2):104-6

21. Jang KY, Hwang SH, Kwon KS, Kim KR, Choi HN, Lee NR, Kwak JY, Park BH, Park HS, Chung MJ, et al. SIRT1 expression is associated with poor prognosis of diffuse large B-cell lymphoma. Am J Surg Pathol. 2008;32(10):1523-31.

22. Lovaas JD, Zhu L, Chiao CY, Byles V, Faller DV, Dai Y. SIRT1 enhances matrix metalloproteinase-2 expression and tumor cell invasion in prostate cancer cells. Prostate. 2013;73(5):522-30.

23. Kriegl L, Vieth M, Kirchner T, Menssen A. Up-regulation of c-MYC and SIRT1 expression correlates with malignant transformation in the serrated route to colorectal cancer. Oncotarget. 2012;3(10):1182-93.

24. Suzuki K, Hayashi R, Ichikawa T, Imanishi S, Yamada T, Inomata M, Miwa T, Matsui S, Usui I, Urakaze M, et al. SRT1720, a SIRT1 activator, promotes tumor cell migration, and lung metastasis of breast cancer in mice. Oncol Rep. 2012;27(6):1726-32.

25. Marshall GM, Liu PY, Gherardi S, Scarlett CJ, Bedalov A, Xu N, Iraci N, Valli E, Ling D, Thomas W, et al. SIRT1 promotes N-Myc oncogenesis through a positive feedback loop involving the effects of MKP3 and ERK on N-Myc protein stability. PLoS Genet. 2011;7(6):e1002135.

26. Saxena M, Dykes SS, Malyarchuk S, Wang AE, Cardelli JA, Pruitt K. The sirtuins promote Dishevelled-1 scaffolding of TIAM1, Rac activation and cell migration. Oncogene. 2015;34(2):188-98.

27. Byles V, Zhu L, Lovaas JD, Chmilewski LK, Wang J, Faller DV, Dai Y. SIRT1 induces EMT by cooperating with EMT transcription factors and enhances prostate cancer cell migration and metastasis. Oncogene. 2012;31(43):4619-29.

28. Nihal M, Ahmad N, Wood GS. SIRT1 is upregulated in cutaneous T-cell lymphoma, and its inhibition induces growth arrest and apoptosis. Cell Cycle. 2014;13(4):632-40

29. Liang XJ, Finkel T, Shen DW, Yin JJ, Aszalos A, Gottesman MM. SIRT1 contributes in part to cisplatin resistance in cancer cells by altering mitochondrial metabolism. Mol. Cancer Res. 2008:6(9):1499-506.

30. Zhu L, Chiao CY, Enzer KG, Stankiewicz AJ, Faller DV, Dai Y. SIRT1 inactivation evokes antitumor activities in NSCLC through the tumor suppressor p27. Mol. Cancer Res. 2015;13(1):41-9.

31. Chen HC, Jeng YM, Yuan RH, Hsu HC, Chen YL. SIRT1 promotes tumorigenesis and resistance to chemotherapy in hepatocellular carcinoma and its expression predicts poor prognosis. Ann Surg Oncol. 2012;19(6):2011-9.

32. Cha EJ, Noh SJ, Kwon KS, Kim CY, Park BH, Park HS, Lee H, Chung MJ, Kang MJ, Lee DG, et al. Expression of DBC1 and SIRT1 is associated with poor prognosis of gastric carcinoma. Clin. Cancer Res. 2009;15(13):4453-9.

33. Noguchi A, Kikuchi $K$, Zheng H, Takahashi H, Miyagi $Y$, Aoki I, Takano Y. SIRT1 expression is associated with a poor prognosis, whereas DBC1 is associated with favorable outcomes in gastric cancer. Cancer Med. 2014;3(6):1553-61

34. Lee H, Kim KR, Noh SJ, Park HS, Kwon KS, Park BH, Jung SH, Youn HJ, Lee $\mathrm{BK}$, Chung MJ, et al. Expression of DBC1 and SIRT1 is associated with poor prognosis for breast carcinoma. Hum Pathol. 2011;42(2):204-13.

35. Wu M, Wei W, Xiao X, Guo J, Xie X, Li L, Kong Y, Lv N, Jia W, Zhang Y, et al. Expression of SIRT1 is associated with lymph node metastasis and poor 
prognosis in both operable triple-negative and non-triple-negative breast cancer. Med. Oncol. 2012;29(5):3240-9.

36. Kim JR, Moon YJ, Kwon KS, Bae JS, Wagle S, Yu TK, Kim KM, Park HS, Lee JH, Moon WS, et al. Expression of SIRT1 and DBC1 is associated with poor prognosis of soft tissue sarcomas. PLoS One. 2013;8(9):e74738.

37. Chen X, Sun K, Jiao S, Cai N, Zhao X, Zou H, Xie Y, Wang Z, Zhong M, Wei L. High levels of SIRT1 expression enhance tumorigenesis and associate with a poor prognosis of colorectal carcinoma patients. Sci Rep. 2014;4:7481

38. He Z, Yi J, Jin L, Pan B, Chen L, Song H. Overexpression of Sirtuin-1 is associated with poor clinical outcome in esophageal squamous cell carcinoma. Tumour Biol. 2016;37(6):7139-48.

Ready to submit your research? Choose BMC and benefit from:

- fast, convenient online submission

- thorough peer review by experienced researchers in your field

- rapid publication on acceptance

- support for research data, including large and complex data types

- gold Open Access which fosters wider collaboration and increased citations

- maximum visibility for your research: over $100 \mathrm{M}$ website views per year

At BMC, research is always in progress.

Learn more biomedcentral.com/submissions 